\title{
RELATÓRIO DE CAMPO DE VISITA FRUSTRADA À FEDERACIÓN DE MOTOTAXISTAS DE CUIDAD DEL ESTE
}

\author{
Roberto Rigaud Navega Costa ${ }^{1}$ \\ Tatiane dos Santos Navega Costa ${ }^{2}$
}

\begin{abstract}
RESUMO: O presente trabalho tem como objetivo descrever uma ida ao campo de pesquisa, feita por nós, mas que não foi bem sucedida, e como pudemos mudar o foco de nossa atenção a tempo de transformarmos um contratempo em uma fonte de observações valiosas a respeito das diferenças que dois espaços contíguos, as cidades de Foz do Iguaçu e Ciudad del Este, podem acarretar nos ritmos da vida cotidiana de sujeitos diversos, tendo como local de pesquisa o ônibus de linha internacional que liga as duas cidades. Para tanto lançamos mão da observação participante como método de pesquisa, e pudemos ainda avaliar a atuação dos fiscais da Receita Federal brasileira no ato de combater o contrabando e o descaminho, acrescentando observações a um trabalho anteriormente feito por nós. Esperamos, ao final do trabalho contribuir para exemplificar como fizemos o trabalho de campo, e quais conclusões pudemos acrescentar ao estudo de nossa realidade fronteiriça, demonstrando que há uma multiplicidade de modos de se apreender o real, e que podemos ter um olhar múltiplo ao irmos em campo.
\end{abstract}

Palavras-chave: Observação participante; Fronteira; Temporalidade.

\section{INFORME DE CAMPO DE VISITA FRUSTRADO A LA FEDERACIÓN DE MOTOTAXISTAS DE CUIDAD DEL ESTE}

RESUMEN: El propósito de este documento es describiruntrabajo de campo que hemos realizado, pero que no ha tenidoéxito, y cómohemos cambiado nuestro enfoque a tiempo para convertirun revés en una fuente de información valiosa sobre las diferencias que dos espacioscontiguos, lasciudades de Foz de Iguazú y Ciudad del Este, puedenconducir a los ritmos de la vida cotidiana de diversos sujetos, teniendo como lugar de investigaciónelautobús internacional que conecta las dos ciudades. Con este fin, utilizamos laobservación participante como método de investigación, y tambiénpudimosevaluarlasacciones de los inspectores de Receita Federal de Brasil enelacto de combatirel contrabando y eldescamino de fondos, agregando observaciones a untrabajo realizado previamente por nosotros. Esperamos, al final del trabajo, ayudar a ejemplificarcómohicimoseltrabajo de campo y quéconclusionespodríamos agregar al estudio de nuestrarealidadfronteriza, demostrando que hay una multitud de formas de captar lo real y que podemos tener una mirada múltiplea medida que avanzamosenel campo.

\footnotetext{
${ }^{1}$ Bacharel em Filosofia; Mestrando no PPG em Sociedade, Cultura e Fronteiras, Unioeste, Foz do Iguaçu. E-mail: ramosnavega@gmail.com

${ }^{2}$ Pedagoga, Psicóloga, Psicopedagoga, Neuropsicóloga.Coordenadora do curso de Pedagogia e Docente na Uniamérica, Foz do Iguaçu. E-mail: navegapsicologia@gmail.com 
Palabras-clave: Observación participante; Frontera; Temporalidad.

\section{INTRODUÇÃO}

Uma fronteira nos apresenta um laboratório a céu aberto extremamente rico, dando-nos oportunidades variadas de observação à custa de um pequeno deslocamento. Estando a pesquisar o combate ao contrabando e ao descaminho na fronteira Brasil Paraguai, entre Foz do Iguaçu e Ciudad del Este, quisemos comparar os sindicatos dos mototaxistas dos dois lados do rio Paraná.

No entanto, não conseguimos a entrevista pretendida com o representante da Federación de mototaxista de Ciudad del Este, que estava ausente no momento em que chegamos ao endereço conseguido a algum custo. Tendo perdido a viagem nos pegamos observando um fato novo, para o qual não havíamos prestado nenhuma atenção até então, a saber, a diferença de ritmo entre as duas cidades citadas acima.

Assim, esta nota de pesquisa de campo tem como finalidade demonstrar como podemos aproveitar outras fontes de conhecimento que a realidade nos fornece, e compartilharmos com os demais pesquisadores dados obtidos em campo, nesta data, e que enriquecera nosso entendimento a respeito das interações tempo-espaço.

A observação participante, utilizada quase que por acaso, já que decidimos utilizar de um olhar científico na volta de nossa tentativa frustrada de entrevista, foi o método escolhido para obtermos os dados que necessitamos para organizar esta descrição. Ainda fizemos relação dos fatos observados com textos que produzimos anteriormente, e com leituras anteriores.

Abaixo descreveremos os acontecimentos em campo e após discutiremos os resultados. Para maior conhecimento do procedimento, dos percalços de pesquisa e dos dados que elencamos posteriormente neste texto sugerimos a consulta da bibliografia, que se ateve ao mínimo necessário para a complementação deste entendimento.

\section{OBSERVAÇÕES}

A atividade foi frustrada pelo fato de nós termos chegado à Federación de Mototaxistas de Ciudad del Este muito cedo pela manhã, e somente ali ficamos sabendo 
que o sr. Ever Olmedo (Alemán), presidente da federação em estudo, apenas comparece ao local bem mais tarde.

No entanto, já imaginávamos que tal fato poderia vir a ocorrer, já que não houve contato antecipado entre as partes, e sequer sabíamos se seríamos bem recebidos pelo representante da categoria dos mototaxistas de Ciudad del Este ou não, e já havíamos passado por percalço semelhante em Foz do Iguaçu, quando procuramos contato com o presidente do sindicato de mototaxistas deste município.

Mas, nem tudo foi perdido naquela manhã, pois pudemos realizar outras observações, principalmente quanto ao procedimento diferenciado dos ônibus "de linha" que atendem tanto a Foz do Iguaçu, quanto a Ciudad del Este. Também, pudemos relembrar fatos concernentes ao procedimento da Receita Federal do Brasil, no que tange à abordagem dos passageiros dos mesmos ônibus citados acima e à fiscalização do contrabando e do descaminho.

Para minha sorte consegui tomar o mesmo ônibus, da viação Riza, com o mesmo motorista, o que nos permitiu verificar as diferenças de procedimento por parte do motorista e dos passageiros quando se está indo do Brasil para o Paraguai, e na volta, quando se vem do Paraguai ao Brasil. Pudemos observar fatos que passavam desapercebidos, apesar do tempo que já vínhamos empregando em tais observações.

A passagem do ônibus custa onze mil guaranis, ou sete reais, e o coletivo é de um tipo bem antigo, mal conservado, construído pela empresa brasileira Marcopolo, num modelo bem conhecido no Brasil, e que era novo na década de 1990 e início dos anos 2000. Neste veículo não havia catraca e o motorista fazia as cobranças e dava o troco aos passageiros que iam entrando.

Assim, quando fomos de Foz do Iguaçu para Ciudad del Este não havia nada de novo a ser observado em relação ao que já acontecia antes, e não havia diferença entre nenhum dos ônibus que temos em Foz do Iguaçu. Há uma rota a ser cumprida e o veículo segue seu rumo, apenas sendo parado pelo engarrafamento e pelos passageiros que sobem e descem do ônibus conforme seus interesses.

$\mathrm{Na}$ volta, no entanto, o rádio do coletivo já estava ligado a uma certa altura incômoda, mas os passageiros não prestavam a atenção, o que nos sugere que se trata de uma situação normal naquele contexto. Esta linha de ônibus vai da rodoviária internacional de Foz do Iguaçu até a rodoviária de Ciudad del Este, que está localizada 
ao lado de um estádio de futebol e de uma espécie de mercado municipal. E daí volta até a rodoviária de Foz do Iguaçu novamente.

As músicas no rádio davam o fundo musical para minhas observações, que no início tiveram o ritmo de músicas "pop” dos anos 1980-1990. Com o ônibus seguindo lentamente pelo eixo principal de tráfego daquela parte da cidade, um eixo sul-norte, ladeado de lojas fechadas, para alugar ("se alquila"), com "moradores de rua" abaixo das marquises das mesmas, num cenário que nos recordava o Rio de Janeiro na mesma década de 1980-1990, pós governos Sarney e Collor.

Do outro lado da pista havia uma sequência enorme de praças e de campos de futebol, numerados, razoavelmente bem conservados, com cercas em volta, uma estrutura impressionante. Mas, nenhuma das praças e nenhum dos campos de futebol estavam sendo usados. A explicação pode variar desde o fato de ser um dia comum de semana e de as pessoas estarem estudando ou trabalhando, até o fato de ser uma obra que não despertou o interesse dos moradores da cidade.

Quando o coletivo vira em direção ao eixo principal que vai da Ponte da Amizade em direção ao oeste do país, o motorista simplesmente para o ônibus, desce do mesmo e vai conversar com uma vendedora de comida que trabalha abaixo de uma passarela de pedestres, compra um copo grande de café com leite (uns 300ml) e um salgado típico do local, uma espécie de empanada assada.

Neste momento começa a tocar no rádio uma canção dos anos 1960, Unchainedmelody, música de The Righteous Brothers, e era como se estivéssemos em outro tempo, pois não havia da parte do motorista e dos demais passageiros nenhuma preocupação com o tempo perdido naquela parada, que para nós era desnecessária, mas que como possibilidade de observação participante, já que éramos também passageiros, se demonstrava um ganho de conhecimento inesperado.

E o cantor fazendo o fundo musical (Oh, my love, my Darling - I'vehungered, for your touch - A long, lonely time - Time goes by soslowly - And time can do somuch Are you still mine?) nos deu a deixa para entender o que se passava - e que pudemos perceber melhor com o restante da viagem - que aquele ônibus, naquela parte do trajeto, obedecia a uma lógica temporal diferenciada da lógica que se aplicava no Brasil, pelo menos o da minha experiência. 
Aparentemente não havia compromisso com a pressa, e este tempo já estava incluso no cômputo total da viagem, e além disso, contava com a complacência dos passageiros, que já deveriam acrescentar esta parada a seu cronograma interno, sabendo que aconteceria e que era inevitável. Assim, após uns cinco minutos o motorista retornou ao veículo e partiu com o mesmo em direção ao microcentro de Ciudad del Este.

No primeiro ponto do microcentro o motorista parou novamente, mais uns três minutos, dando tempo de ouvirmos mais uma música alta em seu rádio. Não anotamos qual foi a canção, mas se não lembramos não deve ter sido significativa para o momento. Um ponto a ser observado é o fato de em cada parada longa que o motorista faz o motor do veículo continuar ligado, lançando dentro do coletivo um cheiro bem forte e desagradável de óleo diesel queimado, que com a proximidade de bocas de lobo ao longo da pista asfaltada se misturava com o cheiro de esgoto, um problema nesta parte da cidade, e com o cheiro de fritura que vinha dos ambulantes locais.

Após passarmos à segunda "rotunda" - estrutura circular que distribui o trânsito e que dispensa semáforos - conforme é nomeado no Paraguai, o motorista parou novamente, no rádio tocava agora uma música de Marina Lima, "fullgás", e gastamos mais uns cinco minutos naquele local. Como era um ponto movimentado, com muitos mototaxistas e vans da associação A.T.A.C.A, pudemos perceber que a estratégia da empresa de ônibus era a de tentar pegar a maior quantidade possível de passageiros, o que justificaria a demora naquele ponto e no seguinte. Ao mesmo tempo, o gasto de combustível, a espera dos demais passageiros e a oferta considerável de ônibus - muitas vezes há dois deles parados esperando passageiros - sugere que não haveria necessidade deste expediente.

Novo ponto, em frente a loja mais procurada por turistas e sacoleiros em Ciudad del Este, a Mega Eletrônicos, que tem cinco andares somente de estoque, com eletrônicos dos mais diversos. Não estranhamos também ser o ponto onde maior número de passageiros entra no coletivo, que também parou por uns outros cinco minutos. Pouco antes de sua saída o rádio começou a tocar "Não quero dinheiro (só quero amar)", de Tim Maia, com o seu: Quando a gente ama não pensa em dinheiro - Só se quer amar, se quer amar, se quer amar. 
Daí o veículo foi se encaminhando para a Ponte da Amizade, seguindo lentamente o ritmo do tráfego, se dirigindo para a aduana da Receita Federal do Brasil, onde o ritmo passou a ser outro, era agora o ritmo da fiscalização, da revista, da suspeita. A nossa posição era muito cômoda, pois não havíamos tentado passar com nada comprado nas lojas paraguaias e tivemos tempo para prestar atenção a cada fato ocorrido no local.

Quando paramos na pista própria para ônibus, no lado direito de quem entra na aduana, já havia três fiscais da Receita Federal nos aguardando. Eram três pessoas experientes, devem estar quase para se aposentar, e já devem ter visto muita coisa naquela parada, pois se separaram em atividades diversas. Uma fiscal entrou pela frente do veículo e já foi nos dando bom dia, o que é inusual nestes procedimentos, outra ficou nos olhando pelo lado de fora, como quem procura por uma movimentação suspeita. $\mathrm{O}$ terceiro entrou pelos fundos do ônibus e foi se dirigindo para a frente.

A fiscal da frente foi muito minuciosa, pois verificou bolsa por bolsa dos passageiros, e ainda afastou cada um de nós dos bancos, para ver se havia algo em nossas costas, sendo que foi a primeira vez que víamos este procedimento. Levantou alguns cobertores, apertou, balançou, na tentativa de sentir algo escondido no meio da embalagem. O curioso é que um destes cobertores tinha uma estampa verde na forma de folhas de maconha.

A cordialidade da fiscal não combinava com a atividade de revista, mas aliviava a tensão inerente ao processo. É como se algo infantil em nós se apresentasse e receasse em ser descoberto em algo de errado que havíamos feito. Na nossa vez, após o bom dia da fiscal e o pedido para que nos afastássemos do banco, para ver nossas costas, acreditávamos que teríamos a mochila revistada, o que não ocorreu - para nosso desapontamento.

Os demais passageiros, da parte de trás do coletivo, já haviam sido revistados pelo fiscal que veio dos fundos do ônibus e pouco após nossa vez na revista o veículo foi liberado. O motorista saiu lentamente da aduana e nos encaminhamos para a pista de tráfego novamente, dissipando o cheiro de óleo diesel que o motor velho queimou inutilmente naqueles intermináveis minutos de combate ao contrabando e ao descaminho. 
A música não era mais ouvida por nós, não pela redução do volume, mas pela competição de sons externos, já que ao sair da aduana o motorista "magicamente" mudou de modo de agir. Acelerou, parou agilmente de ponto em ponto onde deixava os passageiros, parando o tempo necessário para abrir, descarregar, fechar portas e partir. Era como se houvesse acontecido uma troca de condutor no veículo.

Daí até ao TTU (terminal de transporte urbano), onde descemos, o trajeto foi normal, como se sempre houvesse sido desta forma. Ágil, preciso, cronométrico, econômico, como se o rádio inaudível estivesse cantando construção de Chico Buarque: "tijolo por tijolo num desenho lógico... seus olhos embotados de cimento e tráfego", mas nunca saberemos o fundo musical que regia aquele novo ritmo.

\section{CONSIDERAÇÕES FINAIS}

A ideia principal destas notas de pesquisa de campo é a de demonstrar que não há ida ao campo que seja totalmente um desperdício de tempo e de recursos, como já exposto por Rosana Pinheiro-Machado (2009) em sua tese de doutorado, quando não conseguia fazer com que sua intérprete e guia a levasse onde ela queria, tendo que se deixar levar e tentar auferir algum ganho para a pesquisa durante o campo.

Aprendemos que os líderes sindicais no Paraguai fazem o próprio horário - a exemplo do Brasil, apesar de seus representados chegarem bem cedo a seus pontos de mototáxi, no caso desta categoria. No entanto a certeza apenas teremos quando houver uma entrevista efetiva com o representante da categoria em Ciudad del Este, por enquanto é apenas especulação, que uma única ida a este campo não permite confirmar.

E mais importante foi o fato de encontrarmos este estranho funcionamento, em dois tempos, do sistema de transporte internacional entre Brasil e Paraguai, passando na fronteira ligada pela Ponte da Amizade. Havendo um tempo, para o mesmo veículo e o mesmo motorista, em Foz do Iguaçu e outro tempo para Ciudad del Este. Como se o lugar abrigasse uma inércia própria, que vai se modificando na medida em que se passa a outro lugar.

Nós nunca teríamos observado tal fato se utilizássemos de um outro meio de transporte, e nunca teríamos presenciado a postura dos fiscais da Receita Federal do Brasil na aduana, agindo de uma forma bem particular, própria e exclusiva daqueles três 
agentes. Costa e Cardin (2019) já haviam analisado tanto o conceito de tática e de estratégia, a primeira empregada por sacoleiros na passagem pela Ponte da Amizade, e a segunda pelas forças de combate ao contrabando e ao descaminho, e esta nota de campo pode agregar mais dados práticos de uma e outra ação.

Este campo foi, também, um exemplo de observação participante, mesmo sem querer nos inserimos em uma realidade, a analisamos e fizemos parte dela, apesar do completo desconhecimento da parte dos demais passageiros do coletivo, do motorista e dos fiscais da aduana, tudo o que vivemos foi real, sem acréscimo de atenção - caso soubessem o que estávamos a fazer - e sem atuação de nenhum dos sujeitos analisados.

Esperamos ter contribuído para o trabalho de demais estudantes e de profissionais, que estejam utilizando entrevistas, trabalhos de campo, e observação participante, para que atentem para os detalhes que podem passar despercebidos por nós, em nosso cotidiano, e que podem não receber o tratamento analítico que merecem.

Apontamos, também, que tanto a diferença de temporalidade, quanto sua articulação com o espaço, podem ser matéria de futuras pesquisas, e que pode haver um grande ganho em conhecimentos a respeito do ser humano em diferentes cenários, mesmo sem trocar de persona, num ponto de vista Jungiano.

\section{REFERÊNCIAS BIBLIOGRÁFICAS}

ALONSO G., Juan Carlos. La Psicología Analítica de Jung y sus aportes a la psicoterapia. Pontificia Universidad Javeriana. Bogotá, Colombia: Universitas Psychologica, vol. 3, núm. 1, enero-junio, p. 55-70, 2004.

ANGROSINO, Michael. Etnografia e Observação Participante. Porto Alegra: Ed. Artmed. 2009.

COSTA, Roberto Rigaud Navega.; CARDIN, Eric G. Táticas Aplicadas por Sacoleiros na Realização do Descaminho na Ponte da Amizade. Revista Alamedas (Unioeste. Toledo), v. 7, nº 1, jan-maio. p. 77-94, 2019.

PINHEIRO-MACHADO, R. Made in China: produção e circulação de mercadorias no circuito China-Paraguai-Brasil. 2009. f 332. Tese (Doutorado em Antropologia Social). Porto Alegre: UFRS, 2009. 